\title{
Centenario de Joaquín Arcadio Pagaza
}

\author{
Fragmento del discurso dicho en \\ $\checkmark$ alle de Bravo, Méx., la noche del \\ 9 de enero de 1939, por. Agustin Yá- \\ ñez, delegado del Instituto Interna- \\ cional de Literatura Iberoamerica- \\ na en la conmemoración centenaria \\ del poeta Pagaza.
}

E1 genio de los hombres gloriosos lleva consigo a los atrios de la inmortalidad el nombre de las ciudades genetrices, porque se cumple así una ley vital de enlace entre la fisonomía y destino humanos con el ambiente de las primeras impresiones y reacciones, cuando el alma párvula se asoma al mundo y se asombra, cuando más tarde siente las llamadas del destino y vislumbra las altas cuestas de la vida. Por eso siete ciudades se disputan el nacimiento de Homero. Reverenciamos a Mantua y a Florencia por la talla semidivina de sus hijos. Las más humildes aldeas cobran alcurnia por la excelsitud de uno solo de sus varones. Pero esto no es un mero presente de gratitud, sino fenómeno de indisolubilidad histórica. Gloriosa es Atenas por su linaje, pero yo no concibo la siempre viva sagacidad de Sócrates, la claridad radiante de Platón, la prodigiosa actualidad de Aristóteles, el vigor de Esquilo, el uncioso terror de Sófocles, 
la rebeldía de Eurípides y Aristófanes; no concibo la orquestación soberbia de Píndaro; ni los milagros de la arquitectura y la escultura atenienses, sin dar por supuesta a Atenas misma, como un conjunto de paisaje, condiciones y estilos de vida, propicios a la epifanía de aquellas individualidades, genuinos frutos de la ciudad que es pasmo y paradigma de los siglos. Alguien ha dicho que Inglaterra es Cromwell; Francia, Richelieu; España, Cisneros; yo me atrevería a cambiar la fórmula en estos términos: Cisneros es España; Richelieu, Francia; Bismarck, Alemania.

Si pues el hombre glorioso da linaje a su ciudad, pero antes ésta dispuso los caminos de la fortuna y trabajó sobre el espíritu del elegido, justamente correspondía iniciar la conmemoración centenaria de Joaquín Arcadio Pagaza a esta ciudad, madre del poeta, asombrosa ventana por donde descubriera a la naturaleza y al mundo.

Podrán luego venir, y vendrán, los graves, solemnes homenajes de doctas corporaciones; la Universidad abrirá su paraninfo; las Academias sus majestuosos recintos; para mí, ningún acto tendrá la emocionada significación de estas loas vallesanas, al mismo tiempo sencillas y profundas, familiares e imponentes. ¿Qué ceremonia más viva y conmovedora como el número inicial del centenario, bajo el cielo opulento del valle, junto a los muros que rodearon el nacimiento del poeta, frente a los montes revestidos con ornamentos de invierno admirablemente verdes, a la sombra de los fresnos de la plaza que movían sus copas con suave cadencia, al abrigo de los aleros añosos, inconfundible hábito de la ciudad, en medio de una muchedumbre en la que predominaban las gentes del campo cuyo sentimiento de la naturaleza vivió y supo expresar con acento de inmortalidad el coterráneo ilustre, lengua acabada y síntesis de los hondos afectos de aquellos hombres, producto de parejas emociones, amador insigne de los sitios que les despiertan devoción cotidiana y son el obligado escenario de su vida y rústicos afanes?; ningún público puede recordar tan hondamente al gran bucólico, ningún lugar mejor para loarlo, como las gentes que perviven en estos campos y como los campos mismos y el va- 
lle que fueron la delicia insobornable, el inexhausto surtidor de inspiración para Joaquín Arcadio Pagaza. $\mathrm{Y}$ ¿qué acto más severo como la translación de los restos del poeta, a las primeras sombras de la noche, entre đevotas luces y la compañía de deudos, amigos y paisanos, ligados a él no por una postiza admiración literaturizante, sino por vínculos cordiales, maciza $\mathrm{y}$ antiguamente arraigados? $\mathrm{Y}$ luego las peregrinaciones a los sitios en que el poeta puso todas sus complacencias:. perpetuar allí la palabra privilegiada y, con ello, revivir, a pleno sol, la insigne figura de quien siendo fiel cantor del terruño, alcanzó proporciones raciales en la comunidad internacional de cuantos hablan español.

Bien ha lucido su indiscutible primacía en estos homenajes la ciudad de Valle de Bravo. Quienes nos hemos asociado a ellos, tenemos la satisfacción de haber celebrado a la ciudad misma, porque, según la forma enunciada, monseñor Pagaza es Valle de Bravo. No creo que la poesía del nacido aquí, hoy hace cien años, tuviese las características que le merecieron el señalado rango que tienen en la República de las letras, si su autor hubiese nacido lejos de estas latitudes; reuniría otras excelencias, pero no sería ya la poesía exuberante, con fragancia de selva, en que transmutó la exuberancia y perfume específicos del valle natal. De mí sé decir que nunca había entendido tan entrañablemente la belleza poética de la obra de Clearco Meonio, como en estos días que he sentido, al amparo de las cordilleras comarcanas, el efluvio de estos aires, y recreado la vista con los imponderables paisajes de vuestra tierra. Ahora me explico la secreta fuerza de aquellos versos, su tersura y limpidez. He hallado la vena rumorosa y cristalina que los alienta, y la afinidad temperamental de Pagaza con los grandes poetas clásicos. En estos días me ha sido dada la íntima fruición de imaginar cómo fué despertando la sensibilidad del poeta; lo he visto niño y adolescente, contemplar desde un viejo balcón, los cielos con sol o con lluvia, los crepúsculos de maravilla, las noches bordadas de estrellas o con luna esplendente; lo he visto saltar las acequias rumorosas, ensimismarse ante el caudal y música de los ríos, trepar las cuestas para ganar la visión ple- 
na del valle; angustiarse por expresar con el lenguaje de la poesía cada tuna de estas impresiones en que lo objetivo de la naturaleza despertaba las más delicadas fibras de la subjetividad, y asociaba así, con su lírico temperamento, el suntuoso espectáculo exterior de su comarca. Para entender a Pagaza en la plenitud de su valía, hay que entender la belleza de Valle de Bravo, como Nepantla, entre las nieves del Popocatépetl y la tibieza del valle de Cuautla, explica la límpida serenidad y la encendida efusión de Sor Juana Inés de la Cruz, como el primor de Taxco explica la sutil delicadeza de Juan Ruiz de Alarcón, como Zamora explica la ternura de Fray Manuel de Navarrete, como el ascetismo de Tepic explica la recóndita melancolía de Nervo, como los jardines y los lejanos peñones épicos de Jerez explican la poesía de Ramón López Velarde.

$\mathrm{Ni}$ el localismo apuntado constituye paradoja, relativamente a la universalidad de los poetas que en él bordan su mensaje. Localismo y universalidad se conjugan, sucediéndose, cuando el primero es algo más que superficie pintoresca y realiza valores de jerarquía superior al agrado; cuando el artista no se contenta con pintar lo que ve, sino sobre el dibujo y color de la copia - sea, como en Pagaza, del escenario natural, o de las fisonomías y costumbres circunstanciales-, expresa una realidad más honda $y$, por tanto, más general. La historia del arte -de modo singular en la literatura-, ofrece una reiterada confirmación de esta verdad: las obras, los tipos de mayor universalismo, cabalmente son también los de mayores esencias nacionalistas; pero es que tan perfectamente intuyen y expresan su realidad, hasta convertirla en episodio de lo universal; de este modo, el nacionalismo auténtico es el que mejor ahonda los caracteres distintivos, el que explora a conciencia las profundidades del alma y la naturaleza regionales; al cabo de esta búsqueda, encuentra los enlaces del universo: todo es uno y lo mismo.

La poesía bucólica se desposa con el paisaje comarcano; pero no para copiarlo, sino para identificar las voces líricas y las externas, el sentimiento del poeta y la belleza del ambiente; cuando esta identificación es perfecta, el artista se oye a sí mis- 
mo mejor, porque la naturaleza se convierte en eco y tornavoz; pero al mismo tiempo estimula e inspira la emoción que se le ha consagrado. Así la poesía bucólica salta de los límites de su circunstancia, al campo del sentimiento, por cuya hondura alcanza universalidad.

Por cuál otro camino halló nuestro Pagaza la afinidad que lo liga con los grandes bucólicos, ni cómo éstos podrían gloriarse en el señorío del humanismo y dilatarse en larga progenie, si no por sus esencias universales, destiladas en la transmutación de la naturaleza al sentimiento? Bajo el velo de los accidentes locales hállase el alma en posesión del infinito, con tal fuerza, que la circunstancia es sólo un símbolo -más perfecto a medida que el poeta lo siente mejor, como Pagaza en su cariño a Valle de Bravo-; un símbolo de los eternos valores que se realizan mediante la idealización de lo anecdótico. Así, en Pagaza, el deleite del campo es símbolo, entre otros, del valor religioso, perdurable en su espíritu.

Este proceso de idealización que tiende a cambiar el localismo en humanismo, explica la estética de la Arcadia, frecuentemente acusada de artificiosa y falsa ; este juicio adolece de resabios de positivismo; en efecto, desde un ángulo de visión naturalista, el país y sucesos de la Arcadia resultan inconcebibles porque no tienen realidad sensible, sino ideal; pero esto mismo es lo que define por completo el carácter humanista de la Arcadia y, en general, de la poesía bucólica, desde los áureos tiempos de su esplendor greco-romano.

$Y$ aquí hallamos nueva significación al centenario de Clearco Meonio, significación que han venido a recordarme las banderas de los países hispanoamericanos puestas en el kiosco de la plaza municipal de este lugar y que, como delegado del Instituto de Literatura Iberoamericana, me importa reiterar. Es la significación humanista que hoy, como nunca, nuestra raza ha de levantar por programa de vida, frente a los riesgos de la hora. Pero un humanismo que no sea sólo erudición y apareje anquilosamiento, sino actualidad viviente; que acepte de lo antiguo los eternos valores humanos, pero que busque otros 
valores y renueve las formas, hasta hacerlas aptas al momento y la inquietud de los hombres de hoy.

Por Pagaza nos acercaremos a los inmarcesibles modelos de la humanidad antigua; pero asimismo habremos de sentir - como aquéllos- nuestras urgencias y responsabilidades, con un ritmo de belleza que añada sentido y fuerza a la vida hispanoamericana.

No ha resultado, pues, contradictorio, hablar del universalismo y de la significación continental de un poeta, sujeto a las delicias de un pequeño valle al que volvía una y otra vez, cuantas le era dable escapar del mundo que lo retuvo.

Natural es que los elementos del paisaje dilecto se asocien al homenaje. Esta tarde, cuando bajo el palio recamado de ocaso, subimos a la Peña por descubrir el soneto de Pagaza allí inspirado, imaginé cómo se acercaba el coro solemne de las montañas, empinándose, con el manifiesto júbilo de sus verdes, ciñendo, aún más, al valle, adelantábasele la teoría rumorosa de los ríos y el intrépido escuadrón de las acequias. Montañas, ríos, acequias, en aquel momento solemne se estrechaban, como si el pastor de este valle tornara sobre la Peña, con el rabel sonoro. Al entusiasmo de los vallesanos se sumaba el tributo espléndido de la naturaleza, en una conjunción de voces cósmicas y humanas, himno de grandiosos acordes para el prócer nacional del humanismo eterno. 